\title{
Possibilities of ultrasound examination of the knee joint in the diagnosis of Hoffa's disease
}

\author{
V.A. Vasilev ${ }^{1}$, A.V. Ivanisenko ${ }^{2}$, I.I. Konovalova ${ }^{1}$, A.F. Lukashuk ${ }^{2}$ \\ ${ }^{1}$ Petrozavodsk State University, Medical Institute, Petrozavodsk, Russian Federation \\ ${ }^{2} \mathrm{PHI}$ “JSC RZD” Department Clinical Hospital at Petrozavodsk railway station, Petrozavodsk, Russian Federation
}

\begin{abstract}
Introduction Hoffa's disease is a common condition, and is a severe pathology of the knee joint in many cases. Ultrasound with its capabilities and advantages can be a convenient method of primary diagnosis of this pathology. However, in the literature there is almost no description of the characteristic ultrasound picture of Hoffa's disease and an analysis of the most common and pathognomonic symptoms. Objective To study ultrasound signs of Hoffa's disease and present the characteristic sonographic complex of its symptoms. Methods Ultrasound examination of the knee joint and arthroscopy of 37 patients diagnosed with Hoffa's disease, confirmed by a comprehensive clinical and instrumental study, was conducted. Results The most characteristic signs of Hoffa's disease in terms of pathological changes are hypertrophy of the Hoffa's fat pad and changes in its structure, which were detected by ultrasound in $62 \%$ and $84 \%$ of cases, respectively. A new symptom, displacement of the patellar ligament, was identified by ultrasound examination of the knee joint according to the standard protocol in $32 \%$ of the examined. The same percentage comprised the patients who had non-specific sonographic symptoms: an increase in the amount of synovial fluid, as well as signs of infrapatellar bursitis. Ultrasound data were compared with the results of arthroscopic examination, their correspondence was determined. Conclusion It has been established that the ultrasound examination of the knee joint according to the standard method enables to identify a complex of symptoms that are pathognomonic for Hoffa's disease. It is recommended to introduce it in the protocol of the conclusion.
\end{abstract}

Keywords: Hoffa's disease, ultrasound, knee joint

\section{INTRODUCTION}

Inflammatory hyperplasia of the knee fat pad as a cause of pain was first described in 1904 by a German orthopaedic surgeon Hoffa and has its name since then [1]. The disease is common enough and in many cases it is a severe pathology resulting in reduced physical and working activity, as well as disability in some cases.

As for terminology, the disease has several names but nowadays the Hoffa' disease and HoffaKastert syndrome are distinguished. The first is more common in women aged 45 to 65 years, caused by hormonal disorders resulting in fat pad hyperplasia. In young people, Hoffa's syndrome (Hoff-Kastert) is more common, the cause of which is traumatic damage to the anterior part of the knee joint $[2,3]$. However, the pathomorphological and pathophysiological manifestations of the disease are similar in both cases. This is a pathology due to fibro-inflammatory hyperplasia of the fat pad and synovial pterygoid folds of the patella region of a traumatic or other origin. The enlarged fat lobules are infringed between the articular surfaces, and this leads to hemorrhages in the fat pad and hyperplasia of adipose tissue.
The clinical picture of the disease is not always clear and may resemble meniscus damage, since the patient's complaints in most cases is pain, often in the same area of the joint, and in some cases, blockage of the joint. Instrumental diagnosis of Hoffa's disease is currently performed with magnetic resonance imaging, ultrasound examination of the knee joint and arthroscopy [3-7]. Ultrasound examination of the knee joint is a convenient method for the initial diagnosis of Hoffa's disease, as it is non-invasive, affordable, of a low cost (relative to other methods), and there are no contraindications to it.

However, there are few works devoted to the possibilities of ultrasound in the diagnosis of this pathology, which mainly compare sonography with other instrumental techniques [3, 7, 8, 9]. There are observations of clinical cases of the disease in which the results of magnetic resonance, sonographic, and other instrumental studies have been analyzed [10]. However, there is no description of the characteristic ultrasound picture of the Hoffa's disease with an analysis of the most common and pathognomonic symptoms in the literature. 
Purpose To study ultrasonic symptoms of Hoffa's disease, to identify the ultrasonic complex of its symptoms characteristic for diagnosis of this disease at the stage of the initial examination of the patient, to compare the findings of ultrasound and arthroscopy of the knee joint.

\section{MATERIAL AND METHODS}

The work was conducted at the ultrasound division of the NIH Department of Clinical Hospital at the Petrozavodsk station of JSC Russian Railways. An ultrasound examination of the knee joints was performed and its results were analyzed in 37 patients with confirmed comprehensive clinical and instrumental study of Hoffa' disease in the period from 2017 to 2019. There were 18 women and 19 men, the age of the examined ranged from 21 years to 66 years (average age, 45.27 years (confidence interval, $45 \pm 3$ ). At the same time, 14 patients (40-60 years old) had an age characteristic of Hoffa' disease, five individuals (20-29 years old) for Hoffa-Kastert syndrome, 10 patients were aged 30-39 years and eight were over 60 years old. Division into certain groups of patients with Hoffa's disease and Hoffa's syndrome was considered inappropriate because of the similarity of the main pathological changes in the knee joint, as well as the difficulty of tracking the history of the disease in some cases.

Microsoft Excel 2016 software was used for calculation of percentage, calculation of the confidence interval for the age of patients. Findings are presented as the number of cases with a particular symptom, as well as their portion in the examined group. Percentage results are rounded to the nearest value according to generally accepted mathematical rules.

The main complaints and medical history data that led to the examination of patients were joint injury in the anamnesis, pain in the joint area, limitation of movements due to pain, and the periodic occurrence of joint locking. The diagnosis was primarily established on the basis of complaints, medical history, examination by an orthopedic traumatologist, and findings revealed by ultrasound of the knee joint. Subsequently, all patients underwent arthroscopic revision of the joint, followed by treatment at the surgical department, during which the presence of
Hoffa's disease was finally verified.

Ultrasound examination of the knee joints was performed on the Siemens Healthineers ACUSON S2000 system according to the standard method. A linear sensor with a frequency range of $5-10 \mathrm{MHz}$ was used; the study was conducted in B-mode. The structures of the knee joint were studied from four approaches: anterior, medial, lateral and posterior. The following parameters were evaluated: the contours of the joint, the condition of the hyaline cartilage, the joint space and the upper inversion, the amount of intra-articular fluid and its nature, the condition of the joint capsule and lateral collateral ligaments, the state of the quadriceps tendon, damage to the patella, patellar and medial ligaments.

Particular attention was paid to the state of the fat pad, its increase in volume, heterogeneity of the echostructure was recorded; the inclusions were analysed as isoechogenic, hyperechogenic, hypoechogenic and anechogenic. The state of the lateral and medial menisci was assessed: their contours, echostructure, and signs of damage. We included one more symptom in the analysis, which was initially absent in the standard protocol of ultrasound examination - a change in the position of the patellar ligament or its elevation above the fat pad.

Arthroscopy of the knee joint was performed in the supine position from standard portals using a Karl Storz arthroscope with 4-mm optics. When revising the joint, the state of the synovial membrane, the amount of intra-articular fluid and its nature, the state of the menisci, the anterior cruciate ligament, the condition of the articular cartilage, the presence of hypertrophy of the fat pad and impingement of its areas in the joint were studied. In the presence of changes in the meniscus and its dislocation that caused blockade of the joint, it was resected and removed. In severe hypertrophy of the fat pad, a change in its structure and signs of impingement in the joint, changed areas were resected.

\section{RESULTS}

We assessed both separate symptoms of knee joint lesions in Hoffa's diseases and their combinations and correspondence to the main pathomorphological changes in this pathology for confirmation of the ultrasound complex of symptoms.

The conditions of Hoffa's fat pad was our special 
focus by analyzing the results of the ultrasound study of the knee joint as its changes are the main pathognomonic sign of the disease. Its hypertrophy was revealed in the majority of the patients (Table 1). Those patients also had the change in the echostructure of the fat pad (Table 2). However, there were eight cases of echostructure changes without hypertrophy of the Hoffa's fat pad. The analysis of echogenicity of these changes showed similar proportion of anechogenic, hypoechogenic and isoechogenic inclusions, but hyperechogenic ones were significantly fewer. Various combinations of different types of inclusions (hypo- and hyperechogenic) that change the echostructure of the fat pad were revealed.

The symptom revealed by us that was not studied previously according to the standard protocol, the change in the position of the patellar ligament, was found in the third of patients; moreover, it was combined with hypertrophy of the fat pad (Table 2) what seems logical as an increased pad displaces the ligament upwards (relative itself in standard ultrasound position) (Fig. 1 and 2).

Table 1

Ultrasound symptoms of the affected knee joint

\begin{tabular}{|l|c|c|}
\hline Ultrasound symptom & Number of patients & \% from the total of the cases studied \\
\hline Hypertrophy of the fat pad & 23 & 62 \\
\hline Changes in the fat pad echostructure & 31 & 84 \\
\hline Hypoechogenic inclusions into the fat pad & 7 & 23 \\
\hline Hyperechogenic inclusions into the fat pad & 2 & 29 \\
\hline Hypo- and Hyperechogenic inclusions into в the fat pad & 9 & 23 \\
\hline Isochogenic inclusions into the fat pad & 7 & 16 \\
\hline Anechogenic inclusions into the fat pad & 6 & 32 \\
\hline Displacement of the patellar ligament & 12 & 59 \\
\hline Increased amount of the joint fluid & 22 & 51 \\
\hline Signs of infrapatellar bursitis & 19 & 58 \\
\hline Signs of injuries of medial or lateral menisci & 21 & \\
\hline
\end{tabular}

Table 2

Combination of ultrasound symptoms of the knee joint lesion

\begin{tabular}{|l|c|c|}
\hline Combination of ultrasound symptoms & Number of patients & \% from the total of the cases studied \\
\hline $\begin{array}{l}\text { Hypertrophy of the fat pad and change in its } \\
\text { echostructure }\end{array}$ & 23 & 62 \\
\hline $\begin{array}{l}\text { Hypertrophy of the fat pad, change in its echostructure } \\
\text { and displacements of patellar ligament }\end{array}$ & 12 & 32 \\
\hline $\begin{array}{l}\text { Hypertrophy of the fat pad and increased amount of } \\
\text { joint fluid }\end{array}$ & 14 & 32 \\
\hline $\begin{array}{l}\text { Hypertrophy of the fat pad and signs of infrapatellar } \\
\text { bursitis }\end{array}$ & 12 & 32 \\
\hline
\end{tabular}

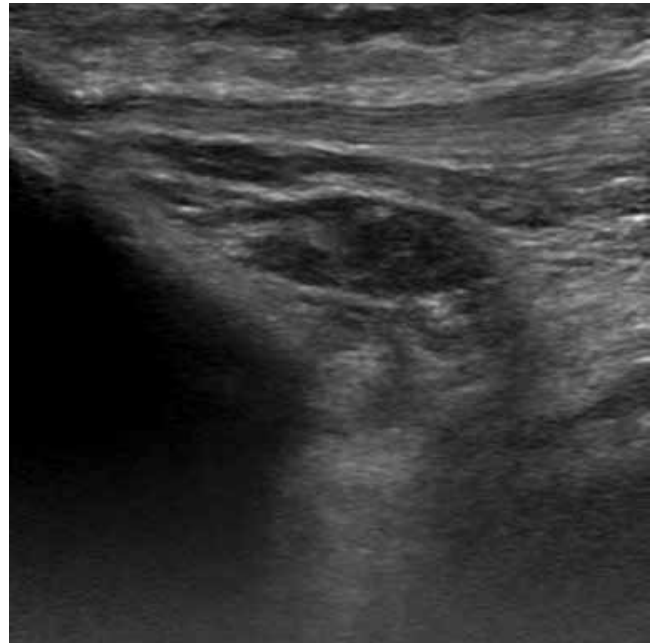

Fig. 1 Hoffa's disease. Hypertrophy of the fat pad. Fat pad echostructure is not heterogenous due to isogenic inclusions. Elevated patellar ligament

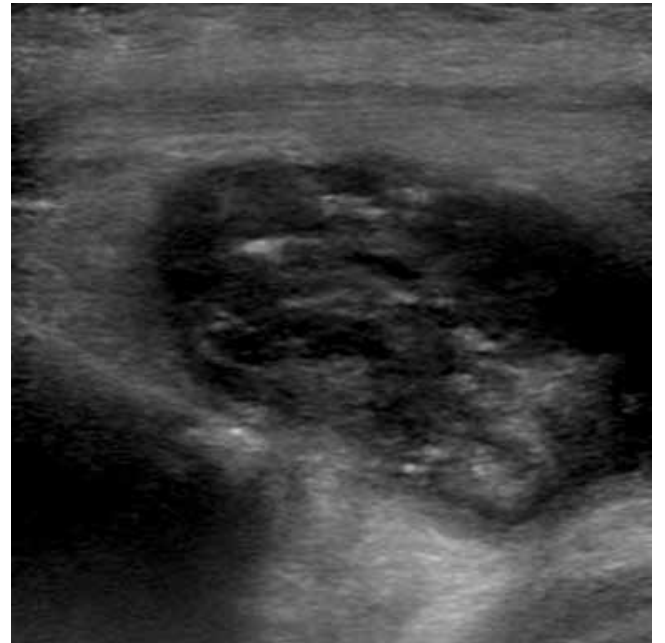

Fig. 2 Hoffa's disease. Hypertrophy of the fat pad. Fat pad echostructure is not heterogenous due to hypo- and hyperechogenic inclusions. Displaced patellar ligament 
An increase in the amount of intra-articular fluid was detected in the majority of the patients. Minor and moderate increase was found in almost equal proportions (Table 1). Moreover, signs of frictional infrapatellar bursitis (synovitis) were also detected in most patients. As for other ultrasound symptoms of knee joint changes, more than half of the cases showed signs of meniscus damage, with changes in the medial meniscus being more frequent than in the lateral one.
The results of arthroscopic examination in the group of patients were changes characteristic of the Hoffa's disease in all cases (Table 3).

In the majority of the cases studied, a pronounced hypertrophy of the fat pad was found; the changes were regarded as moderate only in one case. In addition, in most cases, signs of the fat pad impingement in the joint were found, and in a small part of patients there were signs of joint blocking.

Table 3

Knee joint arthroscopy revision results

\begin{tabular}{|l|c|c|}
\hline Changes revealed & Number of patients & \% from the cases studied \\
\hline Hypertrophy of the fat pad & 36 & 97 \\
\hline Signs of fat body infringement in the joint & 33 & 19 \\
\hline Signs of joint blocking & 7 & 19 \\
\hline
\end{tabular}

\section{DISCUSSION}

The most characteristic signs of Hoffa's disease in terms of pathomorphological changes are hypertrophy of the fat pad and a change in its structure. Increased fat pad and a change in its echogenicity were detected with the ultrasound knee joint study in the majority of the patients examined; thus, they can be considered pathognomonic ultrasonic signs of this pathology (see Table 2). In one third of the cases, these changes were accompanied by a shift in the patellar ligament, which allows us to include this symptom in the number of the Hoffa's disease characteristic features (see Tables 1, 2).

The most specific changes in the structure of the fat pad are hyperechogenic inclusions which are characteristic for hemorrhages as well as anechogenic inclusions that prove swelling of the fat pad which is characteristic of the post-traumatic conditions. The specificity of anechogenic inclusions was confirmed by the fact that all patients with such changes showed an increase in the amount of intra-articular fluid, there were signs of synovitis. However, the data in Table 1 show that changes in different echogenicity were observed in approximately the same percentage of cases.

All patients with a similar combination of symptoms showed an increase in the amount of intra-articular fluid, as well as signs of infrapatellar bursitis, which also may be included in the ultrasound symptomatic complex in Hoffa's disease (Table 2). Synovitis in Hoffa's disease was also reported by other authors [11]. But it should be noted that these changes are nonspecific, as they occur in various pathologies of the knee joint [12]. Accordingly, in conducting differentiated diagnosis and formulating an ultrasound report they should be taken into account only if combined with changes in the size and echo structure of the fat pad and displacement of the patellar ligament.

Case report 1 Patient K., 53 years old was referred to an orthopedic traumatologist with complaints of pain in the right knee joint by walking, limited and painful movements, periodic blocking of the joint. She was studied with ultrasound.

Ultrasound of the right knee joint dated 20.12.2018 revealed a slight thinning of the hyaline cartilage, a slight narrowing of the joint gap, a moderate amount of intra-articular fluid, hypertrophy of the synovial membrane up to $5 \mathrm{~mm}$. The fat pad was increased in volume and its structure was heterogeneous due to anechogenic inclusions. Conclusion of the diagnostic study: "Infrapatellar bursitis. Hypertrophy of the synovial membrane. Hoffa's disease” (Fig. 3).

The patient was hospitalized in the surgical department on 20.01.2019. Local status at admission: the right lower limb was of the regular shape, there was no muscle hypotrophy. Movements in the knee joint were painful, accompanied by crepitus. Extension was limited to 170 degrees. There was no effusion in the joint. The ligamentous apparatus was healthy. Pain on palpation in the projection of the medial meniscus, Baykov's symptom was positive. Pulsation of the foot arteries was preserved. Sensitivity was not impaired. 


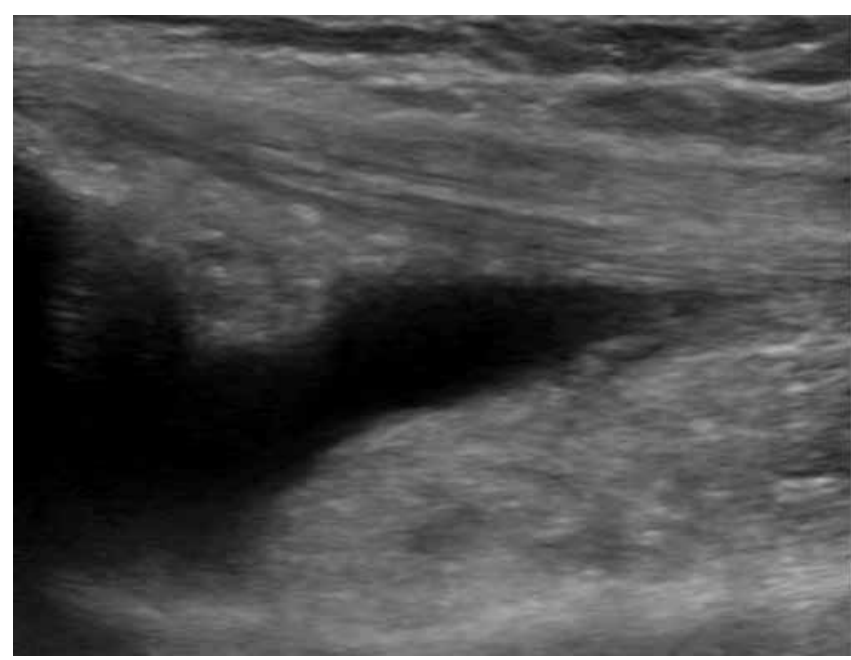

Fig. 3 Patient K. Ultrasound picture of synovitis. Increased amount of fluid in the upper inversion

Arthroscopy was performed on 21.01.2019. The following changes were revealed: chondromalacia of the patella of the 2nd stage, the condyles of the femur of the 2nd to $3 r d$ stages, the condyles of the tibia of the 2nd stage. The anterior cruciate ligament was crossed by fat pad but was traced throughout, was intact. Severe fat pad hypertrophy, its altered folds were impinged in the joint, causing blockages, there was adhesive process. Changed parts of the fat pad, adhesions, and mediopatellar fold were excised.

The postoperative period was uneventful. Pain subsided. There was no synovitis. The patient fully loaded the limb and was discharged to be supervised by a local traumatologist.

Case report 2 Patient N., 45 years old, was examined for complaints of pain in the left knee joint when walking and was referred to ultrasound examination. Ultrasound study of the left knee joint on 14.11.2018 revealed an increased fat pad, heterogeneity of its echostructure due to anechogenic inclusions, and a change in the position (elevation) of the patellar ligament. Conclusion: Hoffa's disease (Fig. 4).

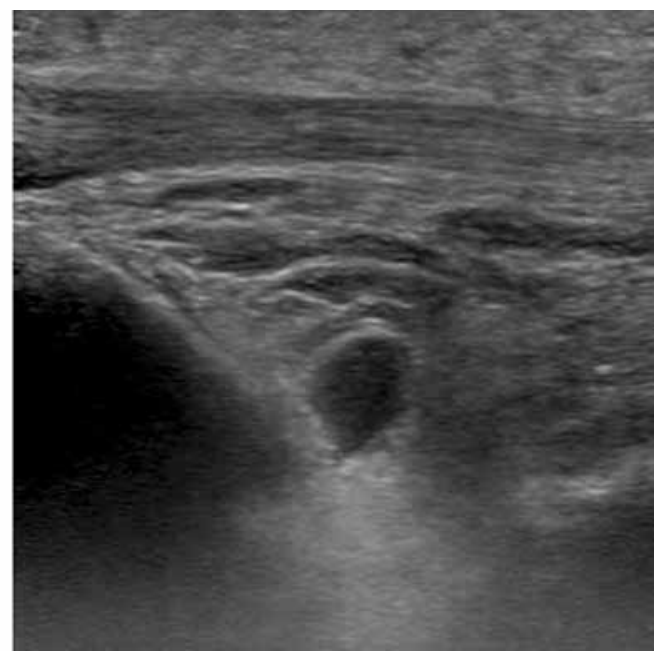

Fig. 4 Patient N. Fat pad is enlarged in volume, its structure is heterogeneous due to anechogenic inclusions

The patient was examined by an orthopedic traumatologist, and was hospitalized on November 21, 2018. The local status at admission: the left lower limb was of the regular shape, there was no muscle hypotrophy. Range of motion in the knee joint was full but painful. There was no effusion in the joint. The ligamentous apparatus was intact. Sharp pain was experienced by the patient during palpation in the projection of the medial meniscus, a positive symptom of Baykov. Pulsation of the foot arteries was preserved. Sensitivity was not impaired. The patient used a cane for walking.

Arthroscopy of the knee joint was performed on 22.11.2018 and revealed: chondromalacia of the patella, femoral condyles and tibia in stage 1 . Menisci were without signs of damage, stable. The anterior cruciate ligament could be traced throughout and was stable. Severe fat pad hypertrophy, which complicated the revision, its altered folds were impinged in the medial part of the joint, blocking the latter. The changed part of the pad and adhesions were excised.

The postoperative period was uneventful. Pain subsided. The patient fully loaded the limb and was discharged to be supervised by a local traumatologist.

\section{CONCLUSION}

Ultrasound examination of the knee joint according to the standard method enables to detect pathomorphological changes, specific to Hoffa's disease. The changes detected by the ultrasound examination in the fat body, as well as other elements of the joint, correspond to the findings of arthroscopic study. According to the results of the study, the most characteristic ultrasonic symptoms of Hoffa's disease are fat pad hypertrophy and a change in its echo structure in combination with a change in the position of the patellar ligament, as well as an increase in the amount of intra-articular fluid and signs of infrapatellar bursitis. However, the last two signs of the diagnostic conclusion should be taken into account only in conjunction with the previous ones. It is recommended to include not only the injury of the patellar ligament but also a change in its position into the standard protocol of the ultrasound study of the knee joint. 


\section{REFERENCES}

1. Hoffa A. The influence of the adipose tissue with regard to the pathology of the knee joint. JAMA, 1904, vol. XLIII, no. 12, pp. 795796. DOI: 10.1001/jama.1904.92500120002h.

2. Valiullin D.R. Morfologiia zhirovogo tela kolennogo sustava u liudei zrelogo vozrasta i ego razvitie $v$ prenatalnom ontogeneze. Extended Abstract Diss. dokt. med. nauk [Morphology of the knee fat pad in people of mature age and its development in prenatal ontogenesis. Dr. med. sci. diss. extended abstract]. Ufa, 2003, pp. 3-4. (in Russian)

3. Karaseva T.Y., Karasev E.A., Ostrovskikh L.A. Sovremennye metody diagnostiki i lecheniia bolnykh s sindromom Goffa-Kasterta [The current techniques of diagnostics and treatment of patients with Hoffa-Kastert syndrome]. Genij Ortopedii, 2008, no. 2, pp. 8183. (in Russian)

4. Draghi F., Ferrozzi G., Urciuoli L., Bortolotto C., Bianchi S. Hoffa's fat pad abnormalities, knee pain and magnetic resonance imaging in daily practice. Insights Imaging, 2016, vol. 7, no. 3, pp. 373-383. DOI: 10.1007/s13244-016-0483-8.

5. Jacobson J.A., Lenchik L., Ruhoy M.K., Schweitzer M.E., Resnick D. MR imaging of the infrapatellar fat pad of Hoffa. Radiographics, 1997, vol. 17, no. 3, pp. 675-791.

6. Bakardzhieva A.N., Diachkov K.A. MRT i UZI-paralleli v otsenke vnutrisustavnykh struktur u bolnykh s zakrytymi povrezhdeniiami kolennogo sustava [MRT- and US-parallels in the assessment of intra-articular structures in patients with closed injuries of the knee]. Genij Ortopedii, 2010, no. 2, pp. 97-102. (in Russian)

7. Briukhanov A.V., Klyzhin M.A. Magnitno-rezonansnaia tomografiia i ultrazvukovoe issledovanie v diagnostike travmaticheskikh povrezhdenii kolennogo sustava [Magnetic resonance tomography and ultrasound investigation in the knee traumatic injury diagnostics]. Radiologiia-praktika, 2007, no. 6, pp. 27-32. (in Russian)

8. Vera-Pérez E., Sánchez-Bringas G., Ventura-Ríos L., Hernández-Díaz C., Cortés S., Gutiérrez M., Pineda C. Sonographic characterization of Hoffa's fat pad. A pilot study. Rheumatol. Int., 2017, vol. 37, no. 5, pp. 757-764. DOI: 10.1007/s00296-0163647-4.

9. Yasser E., Yasser R. Liposynovitis prepatellaris in a child (Hoffa's syndrome): Lessons from MRI. Egyptian Rheumatologist, 2013, vol. 35, no. 3, pp. 181-183. DOI: 10.1016/j.ejr.2013.01.007.

10.Gutierrez L.B., Morgan T.A., Link T., Feeley B., Motamedi D. Utility of Musculoskeletal Ultrasound in the Diagnosis and Treatment of Suprapatellar Fat Pad Impingement: A Case Report. J. Clin. Case Rep., 2016, vol. 6, pp. 837. DOI:10.4172/2165-7920.1000837.

11.Gumerov A.A., Mamleev I.A., Psianchin T.S. Diagnostika sinovita kolennogo sustava u detei [Diagnosing the knee synovitis in children]. Novye Tekhnologii v Detskoi Khirurgii: sb. nauch. tr., posviashch. 100-letiiu med. obrazovaniia v Permskom Krae, 95-letiiu so dnia rozhdeniia A.A. Lishke [Proc. "New Technologies in Pediatric Surgery”]. Perm, 2014, pp. 57-65. (in Russian)

12.Nudnov N.V., Nikolaeva M.V. Ultrazvukovye priznaki vospalitelnogo protsessa v razlichnykh otdelakh kolennogo sustava [Ultrasound signs of the inflammation process in various parts of the knee]. Vestnik Rossiiskogo Nauchnogo Tsentra Rentgenoradiologii, 2013, no. 13. (in Russian) Available at: http://vestnik.rncrr.ru/vestnik/v13/papers/nikolaeva_v13.htm (accessed 11.03.2019).

13.Kinzerskii A.Iu. Ultrazvukovoe issledovanie pri travmakh i zabolevaniiakh kolennogo sustava: prakt. ruk. [Ultrasound examination for injuries and diseases of the knee: practical guide]. Cheliabinsk, Cheliabinskaia Gos. Med. Akad., 2010, 40 p. (in Russian)

Received: 27.06.2019

\section{Information about the authors:}

1. Valerii A. Vasilev, M.D., Ph.D.,

Petrozavodsk State University, Medical Institute, Petrozavodsk, Russian Federation,

Email: valerij-vasiljev@list.ru

2. Aleksandr V. Ivanisenko,

PHI “JSC RZD” Department Clinical Hospital at Petrozavodsk railway station, Petrozavodsk, Russian Federation,

Email: ivanisenko27.08@mail.ru

3. Ineia I. Konovalova,

Petrozavodsk State University, Medical Institute, Petrozavodsk, Russian Federation,

Email: ineya.konovalova@yandex.ua

4.Aleksei F. Lukashuk,

PHI “JSC RZD” Department Clinical Hospital at Petrozavodsk railway station, Petrozavodsk, Russian Federation,

Email: lukashuk_sn@okb10.ru 